\title{
Effectiveness and cost-effectiveness of an injury prevention programme for adult male amateur soccer players: design of a cluster-randomised controlled trial
}

\author{
Anna M C van Beijsterveldt, ${ }^{1}$ Mark R Krist, ${ }^{1}$ Sandor L Schmikli, ${ }^{1}$ Janine H Stubbe, ${ }^{2}$ \\ G Ardine de Wit, ${ }^{3}$ Han Inklaar, ${ }^{4}$ Ingrid G L van de Port, ${ }^{1}$ Frank J G Backx ${ }^{1}$
}

\begin{abstract}
${ }^{1}$ University Medical Centre Utrecht, Department of Rehabilitation, Nursing Science \& Sports, Utrecht, The Netherlands

${ }^{2}$ Netherlands Organization for Applied Scientific Research (TNO Quality of Life, Department of Health Promotion), Leiden, The Netherlands

${ }^{3}$ Julius Centre for Health Sciences and Primary Care, University Medical Centre Utrecht, Utrecht, The Netherlands

${ }^{4}$ Royal Dutch Football Association (KNVB) Sport Medical Centre, Zeist, The Netherlands
\end{abstract}

\section{Correspondence to} Anna MC van Beijsterveldt, University Medical Centre Utrecht, Department of Rehabilitation, Nursing Science \& Sports F00.810, P0 Box 85500, 3508 GA Utrecht, The Netherlands; a.m.c. beijsterveldt@umcutrecht.nl

This study is registered in the Dutch Trial Register as NTR2416.

Accepted 5 November 2010 Published Online First 21 December 2010

\begin{abstract}
Background and aims Approximately 16\% of all sports injuries in the Netherlands are caused by outdoor soccer. A cluster-randomised controlled trial has been designed to investigate the effectiveness and cost-effectiveness of an injury prevention programme ('The11') for male amateur soccer players. The injury prevention programme The11, developed with the support of the World Football Association FIFA, aims to reduce the impact of intrinsic injury risk factors in soccer.
\end{abstract}

Methods Teams playing at first-class amateur level in two districts in the Netherlands are participating in the study. Teams in the intervention group were instructed to apply The11 during each practice session throughout the 2009-10 season. All participants of the control group continued their practice sessions as usual. All soccer-related injuries and related costs for each team were systematically reported online by a member of the medical staff. Player exposure to practice sessions and matches was reported weekly by the coaches. Also the use of The11 during the season after the intervention season will be monitored.

Discussion Our hypothesis is that integrating the The11 exercises in the warm-up for each practice session is effective in terms of injury incidence, injury severity, healthcare use, and its associated costs and/or absenteeism. Prevention of soccer injuries is expected to be beneficial to adult soccer players, soccer clubs, the Royal Dutch Football Association (KNVB), health insurance companies and society.

\section{INTRODUCTION \\ Background and objectives}

Sport is considered a vital component of an active and healthy lifestyle, reducing the risk of various diseases and contributing to better social and physical performance. The beneficial effects of playing sports must be balanced against injuries that are to some extent inevitable. The total number of acute and overuse sports injuries in the Netherlands is about 3.6 million per year and 38\% of these injuries require medical treatment. ${ }^{1}$ Estimated direct and indirect costs (medical costs and work absenteeism) are $€ 1.3$ billion a year. ${ }^{2}$ In the Netherlands, soccer causes the largest number of injuries each year (19\% of all sports injuries), that is 679000 injuries. ${ }^{1}$ Most soccer injuries are located in the lower extremities, the majority concerning the ankle, knee, or hamstring. ${ }^{3}$ These injuries mainly consist of sprains and strains (50\%) and contusions $(33 \%)^{4}$

Outdoor soccer is a high intensity sport with continuous changes of direction and high-load unipodal actions. Participating in this sport puts high demands on neuromuscular control, agility, and eccentric/plyometric strength. Some intrinsic and extrinsic risk factors associated with soccer injuries have been described, and potential prevention measures have been discussed. ${ }^{5-10}$ Several studies have shown that intervention programmes containing specific exercises can significantly reduce injury risks to the lower extremities. ${ }^{11-18}$ An injury prevention programme called 'The11', developed with the support of the World Football Association FIFA, significantly reduced injury rates $21 \%$ fewer injuries) in Swiss male junior soccer players. ${ }^{19}$ However, this injury prevention effect was not observed in Norwegian female junior soccer players, most likely because compliance with the programme was low. ${ }^{20}$ Our project focuses on male adult soccer players, the largest group of soccer players in the Netherlands.

We developed a research project to accompany the introduction of The11 to prevent injuries in Dutch amateur soccer. The first aim of the present study is to investigate the effectiveness and costeffectiveness of the injury prevention programme The11. The hypothesis is that the The11 exercises, when integrated in the warm-up for each practice session, have a beneficial effect on injury incidence and injury severity, leading to lower medical costs and/or reduced absenteeism from sports, school, and work among male adult soccer players. Given the effect in terms of injury risk reduction found in the Swiss study by Junge et al, ${ }^{19}$ overall costs of soccer injuries in the Netherlands could be reduced by implementing the The11 exercises in outdoor soccer. Until now, cost analysis and costeffectiveness data about injury prevention in soccer are lacking.

The second aim of the study is to monitor the use (whether or not continued) of The11 by coaches during practice sessions in the season following the intervention season, to study longterm compliance.

Here, we describe the study design of the study. At the moment of writing the first part of the study (preparation and intervention season 2009-10) has been accomplished. The other parts 
of the study (follow-up season 2010-11, data analysis and economic evaluation) will be accomplished in subsequent years.

\section{METHODS}

\section{Trial design and randomisation}

This two-armed cluster randomised controlled trial (RCT) focuses on the effectiveness and cost-effectiveness of the injury prevention programme The11 for Dutch male amateur soccer players. In order to avoid contamination, randomisation has taken place at cluster level, viz. the regional competitions. Randomisation was done independently by drawing lots.

\section{Intervention}

The injury prevention programme The11 has been developed with the support of the World Football Association FIFA. The programme aims to reduce the impact of intrinsic injury risk factors in soccer. ${ }^{21}$ It includes 10 exercises focusing on core stability, eccentric training of thigh muscles, proprioceptive training, dynamic stabilisation, and plyometrics with straight leg alignment. The 11th component, fair play advice, is not included in the present trial. The exercises of The11 are the bench, sideways bench, hamstrings, cross country skiing, chestpassing in single-leg stance, forward bend in single-leg stance, figures-of-eight in single-leg stance, jumps over a line, zigzag shuffle, and bounding (table 1). The programme takes about 10-15 min after the players have familiarised themselves with the exercises. Coaches of the intervention group were asked to integrate this intervention programme in the warm-up for each practice session (at least two times a week) during the 2009-10 soccer season. Full implementation of the programme in practice sessions took the coaches about 5 weeks during the pre-season. All teams in the intervention group received 18 exercise mats, to enable them to perform some of the ground exercises, especially if the field was in poor condition.

All coaches of the intervention group were informed by means of a course and practical demonstrations. The Coach Academy of the Royal Dutch Football Association (KNVB) provided instructions for the implementation of The11. This cooperation with the KNVB facilitates collaboration with participating clubs, coaches and players. In addition, individual consultations were provided by members of the research team. The main goal was to motivate coaches, to create awareness of injury prevention strategies, and to impart the necessary knowledge and techniques to incorporate The11 in practice. In addition, the coaches received a detailed information package (DVD, poster, and reader), presenting the basic elements of the injury prevention programme. In the control group, coaches were invited to participate in what they were told would be a study of injury prevention, injury incidence, and characteristics of practice sessions.

\section{Participants}

Two, geographically separated but similar regional districts of Dutch first-class amateur soccer were invited to participate in the study. After allocation of these two districts by the KNVB, officials from the selected districts were contacted personally to ask their permission to conduct the study. Only teams with male players between 18 and 40 years of age were eligible for inclusion. The research team gave the clubs and their first team coaches information about the aims of the trial. The control group was asked to participate in a study on injury incidence and characteristics of practice sessions. The intervention group was informed about the possibility of reducing injury risks by incorporating The11 in their practice sessions. All invited teams have practice sessions 2-3 times a week. Players from both groups were asked to sign an informed consent statement at the start of the intervention season.

Data collection: recording injury, healthcare use and exposure During the pre-season (August 2009), all players were asked to fill in a questionnaire to record baseline characteristics: date of birth, height, weight, nationality, years of experience as a soccer player, educational level, profession, numbers of working hours per week, dominant leg, position in the soccer field, preventive measures taken (such as shin guards, taping, braces), chronic diseases, and prior soccer injuries sustained during the previous year (number and localisation).

During the season, information about exposure to soccer (each practice session and match) was reported by the coach using a weekly computer-based recording form. When a player was not present at a regular practice session or game, the reason for his absence was reported on the exposure form as 'injured' or 'other reason'. Additional time spent playing or practising outside the team context, such as a practice session or game with another team or individual recovery training, was also recorded on the exposure form (time and goal of individual exposure). In addition, the coach of each team in the intervention group reported the use of The11 (time in minutes) on this exposure form.

In both research groups, a paramedic of each team was responsible for recording of the injuries using the Web-Based Injury System (BIS) developed by the Netherlands Organization for Applied Scientific Research (TNO Quality of Life). ${ }^{22}{ }^{23}$ BIS has been developed to record sports injuries and evaluate preventive measures and interventions. During the pre-season, the paramedics of the participating teams recorded injuries to get used to the system. Each team was provided with a laptop with internet access, to support the soccer injury recording. The laptop enabled injury data to be entered directly into BIS, on a secure website. The system is capable of gathering epidemiological information on injuries (location, duration, and type), aetiology (intrinsic and extrinsic risk factors), consequences of injuries (eg, work/school/sports absenteeism), and the volume and type of medical treatment, using so-called injury and recovery forms. TNO provided instructions to the participating teams for monitoring data on injuries and associated healthcare use.

BIS has adopted the basic guidelines of the consensus statement on injury definitions and data collection procedures in soccer. ${ }^{24}$ An injury was defined as: 'any physical complaint sustained by a player that results from a soccer match or soccer practice session, irrespective of the need for medical attention or time loss from soccer activities'.

\section{Compliance}

During the intervention season, practice sessions of each team, selected at random, were monitored by independent observers and members of the research team each month. The purpose of these visits was to verify the actual use and the quality of implementation of the injury prevention programme The11 in the intervention group. This information was used to analyse the consistency of the implementation by coaches. At the same time, coaches were encouraged to give more attention to the topic in order to maintain or enhance compliance. The purpose of the random visits in the control group was to check their actual warm-up (duration and type of exercises) and to record the self-initiated use of preventive measures (specific those of The11) by the teams in the control group. A standardised form 
Table 1 Instructions and repetitions for the exercises of The11

\begin{tabular}{|c|c|c|}
\hline Exercise & Instructions & Repetitions/duration \\
\hline 1. The bench & $\begin{array}{l}\text { Head, shoulders, back, and hips in a straight line, parallel to the ground. Elbows } \\
\text { directly under the shoulders. Lift one leg a few centimetres off the ground. }\end{array}$ & $\begin{array}{l}\text { Hold the position for } 15 \mathrm{~s} \text {. } \\
\text { Repeat twice for each leg. }\end{array}$ \\
\hline 2. Sideways bench & $\begin{array}{l}\text { Upper shoulder, hip, and upper leg in a straight line parallel to the ground. Elbow } \\
\text { directly under the shoulders. From above, shoulders, elbow, hips, and both knees are } \\
\text { in a straight line. Don't drop the hips. }\end{array}$ & $\begin{array}{l}\text { Hold the position for } 15 \mathrm{~s} \text {. } \\
\text { Repeat twice for each side. }\end{array}$ \\
\hline 3. Hamstrings & $\begin{array}{l}\text { Ankles pinned firmly to the ground by a partner. Slowly lean forward keeping upper } \\
\text { body and hips straight. Keep thighs, hips, and upper body in a straight line. Try to } \\
\text { hold this straight body alignment, using the hamstrings, for as long as possible, then } \\
\text { control your fall. }\end{array}$ & Repeat 5 times. \\
\hline 4. Cross country skiing & $\begin{array}{l}\text { Flex and extend the knee of the supporting leg and swing the arms in opposite } \\
\text { directions in the same rhythm. On extension, never lock the knee, and don't let it } \\
\text { buckle inwards. Keep pelvis and upper body stable and facing forwards. Keep pelvis } \\
\text { horizontal and don't let it tilt to the side. Flex and extend each leg. }\end{array}$ & 15 times on each leg. \\
\hline 5. Chest-passing in single-leg stance & $\begin{array}{l}\text { Keep knees and hips slightly bent. Keep weight only on the ball of the foot, or lift heel } \\
\text { from the ground. From the front, hip, knee, and foot of the supporting leg should be } \\
\text { in a straight line. Throw a ball back and forth with a partner. }\end{array}$ & 10 times on each leg. \\
\hline 6. Forward bend in single-leg stance & $\begin{array}{l}\text { As for Exercise 5, but before throwing it back, touch the ball to the ground without } \\
\text { putting weight on it. Always keep knee slightly bent and don't let it buckle inwards. }\end{array}$ & 10 throws on each leg. \\
\hline 7. Figures-of-eight in single-leg stance & $\begin{array}{l}\text { As for Exercise } 5 \text { but before throwing it back, swing the ball in a figure-of-eight } \\
\text { through and around both legs: first around the supporting leg with the upper body } \\
\text { leaning forward, and then around the other leg, standing as upright as possible. } \\
\text { Always keep knee slightly bent and don't let it buckle inwards. }\end{array}$ & 10 throws on each leg. \\
\hline 8. Jumps over a line & $\begin{array}{l}\text { Jump with both feet, sideways over a line and back, as quickly as possible. Land } \\
\text { softly on the balls of both feet with slightly bent knees. Don't let knees buckle } \\
\text { inwards. }\end{array}$ & $\begin{array}{l}\text { Repeat side-to-side } 10 \text { times and } \\
\text { then forwards-backwards } 10 \text { times. }\end{array}$ \\
\hline 9. Zigzag shuffle & $\begin{array}{l}\text { Bend knees and hips so upper body leans substantially forward. One shoulder should } \\
\text { always point in the direction of movement. Shuffle sideways through the zigzag } \\
\text { course as fast as possible. Always take off and land on the balls of the feet. Don't let } \\
\text { knees buckle inwards. }\end{array}$ & Complete course twice. \\
\hline 10. Bounding & $\begin{array}{l}\text { Bring the knee of the trailing leg up as high as possible and bend the opposite arm in } \\
\text { front of the body when bounding. Land softly on the ball of the foot with a slightly } \\
\text { bent knee. Don't let knee buckle inwards during take-off or landing. }\end{array}$ & Cover $30 \mathrm{~m}$ twice. \\
\hline
\end{tabular}

was used to score and evaluate the practice sessions in terms of injury-preventive activities for both groups.

Half way through the season, a meeting was organised for the coaches of the intervention group to evaluate the practical aspects of using BIS and The11. A similar evaluation meeting was organized for the coaches of the control group, allowing them to share experiences with the use of BIS. In addition to monitoring and motivating participants in both research groups, we also attempted to enhance compliance to the study by providing extras such as regular newsletters for all participants (in a different version for each district to avoid contamination), free exercise mats for the teams in the intervention group, a free laptop for all participating teams after completion of the intervention season, talks by famous Dutch soccer coaches, and free tickets for matches of the national soccer team for all participating coaches and paramedics. Finally, compliance was stimulated by providing regular feedback to all participating soccer clubs about the injuries recorded in BIS.

After the intervention season, the coaches from the intervention group took part in a survey to evaluate The11 and the actual use of the programme during the intervention season. Players have filled in a questionnaire to determine their positive and negative aspects of the The11 exercises. The participating coaches and paramedics of the control group have been fully informed about the aims of the study at the end of the intervention season. These coaches have received the same information package about The11 as the coaches in the intervention group.

Before the start of the follow-up season 2010-11, the coaches of the control group will be asked to fill in a similar questionnaire on their opinion about The11 and their expectations about using The11 during practice sessions in the next season. All coaches, of both research groups, will receive a second questionnaire in the first month of the competition season. This questionnaire will enquire after their actual use of The11. The results of the two questionnaires will provide information about the coaches' opinion of The11 and the expected and actual use (whether or not continued) of The11. To validate these results in both research groups, several practice sessions will be observed and scored (eg, in terms of duration and type of exercises in the warm-up) during the second season to determine the actual use and the level of implementation of the The11 exercises in practice sessions.

\section{Outcomes}

The primary outcomes of the study include effectiveness and cost-effectiveness (see 'economic evaluation'). Injury characteristics were recorded during the 2009-10 competitive season, from the first competition match (September 2009) until the last regular competition match of the season (May 2010) and compared between the intervention and control groups. The injury-prevention effect will be determined by monitoring the proportion of injured players in both research groups during one season (injury incidence), and injury severity will be derived from the necessity to have medical treatment and/or from absenteeism. Injury risks for players will be calculated and compared between both research groups.

Secondary outcome parameters are compliance and the quality of the implementation of the prevention programme during the intervention season and the subsequent season. Team compliance as well as player compliance will be calculated for the participating teams of the intervention group during the intervention season. In the follow-up season, the focus will be on quantitative aspects of the implementation of the prevention 
programme, measured by observations of practice sessions and completed questionnaires completed by participating coaches of both study populations. The questionnaires concern the actual use of The11 exercises and possible variations to the programme.

\section{Sample size}

On average, $45 \%$ of all soccer players in the Netherlands get injured at least one a year (ranging from minor to moderate and severe injuries). During the same period, approximately $70 \%$ of the soccer players (mainly males) between 18 and 40 years of age get injured. These conclusions were derived from the national survey on Injuries and Physical Activity in the Netherlands (IPAN), covering 6 years (2000-05) of continuous recording of the nature and extent of sports injuries in the Netherlands. ${ }^{25}$ We estimated that the programme The11 as used in our study would allow a $25 \%$ reduction of soccer injuries, in view of the results reported by Junge et al ${ }^{19}$ and Heidt et al. ${ }^{15}$ For a power of 0.80 and $\alpha$ of 0.05 , an estimated 115 players in each group had to take part in the study during a whole soccer season. Assuming a drop-out risk of $26 \%$, based on the study of Junge et al, ${ }^{19}$ the research team aimed to include a minimum of 155 players in each research arm. Therefore, 12 teams were included in each arm.

\section{Economic evaluation}

The aim of the economic evaluation is to determine cost-effectiveness by relating net cost differences between the intervention and control groups to differences in injury incidence. The cost analysis of soccer injuries has to include healthcare costs and costs of production losses. All costs originating from the injury will be taken into account. Healthcare costs include the expenses of visits to medical specialists, additional visits to other healthcare providers (general practitioners and physiotherapists), prescription medication, resources to improve recovery, hospitalisation, x-rays and other diagnostic procedures. The economic evaluation will assess the balance between costs and effects. Results of both cost and effect measurements will be integrated using cost-effectiveness analysis. All healthcare use will be valued according to Dutch guidelines for cost analysis in healthcare research. ${ }^{26}$ If these guidelines do not apply, cost prices will be calculated using the bottom-up costing method. Costs of production losses are the result of work absenteeism for players with a paid job. Indirect costs of production losses due to soccer injuries will be estimated. These costs will be calculated using the friction cost approach. ${ }^{27}$ Data regarding injury-related costs will be prospectively collected by means of volume questionnaires in BIS. The frequency of medical and paramedical treatment and work/school/soccer absenteeism, multiplied by unit costs, will yield an estimate of the costs at individual level. Severity, as derived from the necessity to have medical treatment and the duration of absenteeism, will be calculated. Subsequently, an estimate of the total costs and severity per research group will be obtained by adding up and averaging the individual records. Finally, intervention costs, that is, costs required to implement the intervention in practice sessions outside an evaluation study context, will be assessed as part of the cost analysis.

If this trial should provide evidence that integrating the The11 exercises in the warm-up results in better outcomes than regular practice sessions, an incremental cost-effectiveness analysis will be warranted. The intervention will be dominant when both the proportion of injured players in the intervention group and net costs are lower than those for the control group. Bootstrapping will be used for pairwise comparison of the mean differences in total costs between the intervention and control groups. CIs will be obtained by bias-corrected and accelerated (BCA) bootstrapping using 2000 replications. Incremental cost-effectiveness ratios will be calculated by dividing the difference between the mean net costs in the intervention group and the control group by the difference in the mean effects of the intervention and the regular soccer practice sessions. These ratios quantify the additional costs (if any) related to the additional health effects that are expected from the intervention. Uncertainty about the cost-effectiveness ratios will be presented using cost-effectiveness planes. Acceptability curves showing the probability that The11 is cost-effective will also be presented, given various thresholds for the investment in costs of the intervention programme (in a situation without cost savings).

\section{Statistical methods}

The intervention effect with a single-factor design will be calculated using both parametric (t-test) and non-parametric (Mann-Whitney or $\chi^{2}$ test) analysis for the following effect parameters: injury profile (body part and type of injury: chronic/ acute); injury incidence; injury incidence per $1000 \mathrm{~h}$ of sports; and costs related to sports injuries. Cox regression will also be used to compare the two research groups. Descriptive statistics of self-reported use of the prevention programme during the RCT in the intervention group will be used to describe compliance. Data on the use of The11, as observed by independent observers and reported by the coaches, will be compared; data from the observations of practice sessions in the control group and intervention group will also be compared.

Continuation of the use of the intervention programme during the second season will be determined from observations and self-reports by the coaches. These data will be compared with the self-reported and observed use of the intervention programme during the trial season.

\section{DISCUSSION}

Prevention of soccer injuries is expected to benefit the players and clubs involved, as well as the KNVB, health insurance companies and society. This cluster RCT has been designed to evaluate the effects of a structured injury prevention programme in adult male amateur soccer. If positive, the findings will support extensive implementation of the intervention programme in training courses for soccer coaches by the KNVB Coach Academy. The strengths of our study include the large study population $(2 \times 12$ participating teams) and the use of a web-based recording system (BIS), as direct, online input into BIS without intermediate steps will avoid data modification or data loss. The addition of a cost-effectiveness analysis to the effectiveness study will provide unique knowledge for the field of soccer injury prevention.

One limitation of the proposed trial is that none of the participants is blinded to group allocation, as the nature of the intervention precludes blinding of players, paramedics, or coaches. To reduce potential confounding, the teams of the intervention and control group are clustered by district and these districts are geographically separated to prevent contamination. We hope to minimise potential bias in the control group by informing the control group as described above. Another study limitation is that we do not know the exact content of all practice sessions, since constant observation is not possible. We attempt to examine the content of the practice sessions in both research groups by regular, systematic, random, and unannounced visits to monitor the practice sessions. In addition, the study is expected to yield data on the compliance of the intervention group with The11. Since previous research has shown that compliance with comparable injury prevention programmes 
tends to be low, this is also a special concern in the present study. ${ }^{19}{ }^{20}$ Although a study with 'The11+', a revised version of The11, found that compliance was higher than with the original programme, we preferred to use the original The $11 .^{28}$ The present study tries to improve compliance by monitoring the practice sessions, providing incentives (as described above in the 'compliance' section) and organising meetings with coaches and paramedics of the participating teams.

Acknowledgements We are grateful to the district management of the Royal Dutch Football Association (KNVB), representatives of the participating soccer clubs (board members, coaches, and medical staff) and the soccer players involved.

Funding The Netherlands Organisation for Health Research and Development (ZonMw), Laan van Nieuw Oost Indië 334, The Hague, the Netherlands and Royal Dutch Football Association (KNVB) Sport Medical Centre, Woudenbergseweg 56-58, Zeist, The Netherlands.

\section{Competing interests None.}

Ethics approval The study protocol has been approved by the Medical Ethics Committee of the University Medical Centre Utrecht, reference number 08/263.

Provenance and peer review Not commissioned; not externally peer reviewed.

\section{REFERENCES}

1. Factsheet on sports injuries (in Dutch), Amsterdam: Consumer Safety Institute, 2010.

2. Letsellastmodel 2008, (in Dutch). Amsterdam: Consumer Safety Institute and Erasmus Medical Center Rotterdam, 2010.

3. Wong $\mathbf{P}$, Hong Y. Soccer injury in the lower extremities. Br J Sports Med 2005:39:473-82.

4. Arnason A, Sigurdsson SB, Gudmundsson A, et al. Risk factors for injuries in football. Am J Sports Med 2004;32(Suppl 1):5S-16.

5. Aaltonen $\mathbf{S}$, Karjalainen $\mathrm{H}$, Heinonen $\mathrm{A}$, et al. Prevention of sports injuries systematic review of randomized controlled trials. Arch Intern Med 2007; 167:1585-92.

6. Alentorn-Geli E, Myer GD, Silvers $\mathrm{HJ}$, et al. Prevention of non-contact anterior cruciate ligament injuries in soccer players. Part 2: a review of prevention programs aimed to modify risk factors and to reduce injury rates. Knee Surg Sports Traumatol Arthrosc 2009;17:859-79.

7. Ergen E, Ulkar B. Proprioception and ankle injuries in soccer. Clin Sports Med 2008:27:195-217.

8. Inklaar H. Soccer injuries. II: Aetiology and prevention. Sports Med 1994;18:81-93.

9. Junge A, Dvorak J. Soccer injuries: a review on incidence and prevention. Sports Med 2004;34:929-38.

10. Petersen J, Holmich P. Evidence based prevention of hamstring injuries in sport. Br J Sports Med 2005;39:319-23.
11. Askling C, Karlsson J, Thorstensson A. Hamstring injury occurrence in elite soccer players after preseason strength training with eccentric overload. Scand J Med Sci Sports 2003;13:244-50.

12. Caraffa A, Cerulli G, Projetti $M$, et al. Prevention of anterior cruciate ligament injuries in soccer. A prospective controlled study of proprioceptive training. Knee Surg Sports Traumatol Arthrosc 1996:4:19-21.

13. Emery CA, Meeuwisse WH. The effectiveness of a neuromuscular prevention strategy to reduce injuries in youth soccer: a cluster-randomised controlled trial. $\mathrm{Br} \mathrm{J}$ Sports Med 2010:44:555-62.

14. Grindstaff TL, Hammill RR, Tuzson AE, et al. Neuromuscular control training programs and noncontact anterior cruciate ligament injury rates in female athletes: a numbers-needed-to-treat analysis. J Athl Train 2006:41:450-6.

15. Heidt RS Jr, Sweeterman LM, Carlonas RL, et al. Avoidance of soccer injuries with preseason conditioning. Am J Sports Med 2000;28:659-62.

16. Hewett TE, Myer GD, Ford KR, et al. Biomechanical measures of neuromuscular control and valgus loading of the knee predict anterior cruciate ligament injury risk in female athletes: a prospective study. Am J Sports Med 2005;33:492-501.

17. Mandelbaum BR, Silvers HJ, Watanabe DS, et al. Effectiveness of a neuromuscular and proprioceptive training program in preventing anterior cruciate ligament injuries in female athletes: 2-year follow-up. Am J Sports Med 2005:33:1003-10.

18. Verhagen $\mathbf{E}$, van $\operatorname{der}$ Beek $A$, Twisk J, et al. The effect of a proprioceptive balance board training program for the prevention of ankle sprains: a prospective controlled trial. Am J Sports Med 2004:32:1385-93.

19. Junge A, Rosch D, Peterson L, et al. Prevention of soccer injuries: a prospective intervention study in youth amateur players. Am J Sports Med 2002;30:652-9.

20. Steffen K, Myklebust G, Olsen OE, et al. Preventing injuries in female youth football-a cluster-randomized controlled trial. Scand J Med Sci Sports 2008;18:605-14.

21. Dvorak J, Junge A. Football medicine manual. Zurich: F-MARC, 2005:81-93.

22. Stege JP, Stubbe JH, van Hespen ATH, et al. Injuries in professional Dutch football: a prospective cohort study. Br J Sports Med 2008;42:544.

23. van Hespen ATH, Stubbe JH, Stege JP, et al. Blessure Informatie Systeem (B/S): resultaten hockey, korfbal, schaatsen en paardensport. Trendrapport Bewegen en Gezondheid 2006/2007 (in Dutch). Leiden: TNO Quality of Life, 2008.

24. Fuller CW, Ekstrand J, Junge A, et al. Consensus statement on injury definitions and data collection procedures in studies of football (soccer) injuries. Clin J Sport Med 2006;16:97-106

25. Schmikli SL, Backx FJ, Kemler HJ, et al. National survey on sports injuries in the Netherlands: target populations for sports injury prevention programs. Clin J Sport Med 2009;19:101-6.

26. Oostenbrink JB, Bouwmans CAM, Koopmanschap MA, et al. Handleiding voor kostenonderzoek. Methoden en standaard kostprijzen voor economische evaluaties in de gezondheidszorg (in Dutch). Amstelveen: College voor Zorgverzekeringen, 2004

27. Koopmanschap MA, Rutten FF, van Ineveld BM, et al. The friction cost method for measuring indirect costs of disease. J Health Econ 1995;14:171-89

28. Soligard T, Myklebust G, Steffen K, et al. Comprehensive warm-up programme to prevent injuries in young female footballers: cluster randomised controlled trial. $B M J$ 2008;337:a2469. 